\title{
The Effects of Game Players' Social Intelligence on Social Support and Psychosocial Problem Factors in a 2-Wave Longitudinal Study
}

\author{
Lee, Hye Rim \\ Konkuk University \\ hyerimlee1207@gmail.com
}

\author{
Jeong, Eui Jun \\ Konkuk University \\ jeong12@konkuk.ac.kr
}

\author{
Lee, Sung Je \\ Konkuk University \\ rmflsdpfvm@naver.com
}

\begin{abstract}
Although digital gaming may be considered a social medium, no prior study has investigated how young players' social intelligence affects their psychosocial problems (aggression, depression, loneliness, and stress) and social functioning (relationships with parents and peers). The primary aim of this study was to investigate the relations between social intelligence and psychosocial outcomes. Using data from 1364 online game players in Korea, we conducted a 2-wave longitudinal study at 6-month intervals for tracking the same person. The findings indicated that level of social intelligence was negatively related with all measures of adverse emotions and positively related with relationships with parents and peers over time. The findings and implications are discussed.
\end{abstract}

\section{Introduction}

Digital games are played by millions of people globally and can be considered one of the most popular types of social leisure activity [1, 2], especially among adolescents [3, 4]. Among all life stages, adolescence is the one of the most important periods of rapid growth, involving a potentially turbulent emotional transition [5,6] that affects both cognitive and psychosocial functioning [7]. Although the transition through adolescence is inevitable, the resulting phenomenon of adolescent stress has emerged [8], which is potentially related to aggression, depression, and loneliness [9, 10, 11]. Given that the period of adolescence represents a time of transformations in social relationships, among many other factors that may affect online game players, the present study sought not only to extend previous research on social risk factors, but also to examine whether similar aspects of parent- and peerrelated social functioning are related to social intelligence in adolescents.
Social intelligence encompasses diverse cognitive, affective, and behavioral concepts relating to a person's perceived efficiency in social environments. It can be extended and conceptualized from many perspectives, such as from reality to adolescents' diverse relationships in the virtual world. Although gaming activity is strongly related to various social factors, which might vary depending on players' social intelligence, no prior study has examined social factors (relationships with parents and peers) together with psychosocial problem factors (aggression, depression, loneliness, and stress) with respect to players' social intelligence. Thus, this study aimed to make novel contributions by revealing the relationships between these factors in adolescents between 11 and 17 years old. Using a large 2-wave longitudinal sample, this study examined whether psychosocial problem factors (aggression, depression, loneliness, and stress), parent-child communication, peer emotional support, and gaming time are associated with levels of social intelligence among Korean adolescents.

\subsection{Social intelligence and psychosocial problem factors}

Social intelligence refers to a person's ability to use social skills in order to accomplish interpersonal goals [12] and can be used to predict whether or not a person's behavior will show adequate adaptation in interpersonal relationships [13]. Social intelligence has been described as a person's ability to cope with life's diverse situations [14]. Additionally, social intelligence has been associated with improved social acceptance and behavioral adaptability or flexibility [15]. Additionally, intelligence is highly correlated with cognitive control, which has been shown to inhibit the effects of activated negative feelings, such as angry and hostile thoughts [16-17].

Considering these findings together, social intelligence not only allows individuals to regulate their cognitive processes, but can also affect their 
ability to cope with life's circumstances.

As online gaming activity has been considered a social tool [18], players' social intelligence might affect their affective and cognitive characteristics in various ways. Wallenius and colleagues[19] found that parent-child communication and social intelligence moderated the association between digital game playing and aggression. This implies that players with high social intelligence and greater interaction with their parents are better equipped to deal with aggression. They also showed that higher intensity playing was associated with decreased indirect aggression among 13-year-old boys with high levels of social intelligence. It is therefore likely that socially intelligent players might show reduced aggression in the virtual world. This is in line with previous studies arguing that social intelligence can be considered to be a regulation of cognitive processes [20]. Wilkowski and Robinson [17] also suggested that cognitive regulation might play a critical role in managing negative emotions, such as hostile thoughts and feelings.

In addition to aggressive tendencies, other negative emotions like depression, loneliness, and stress can also be affected by social intelligence among those who enjoy online games. This is because games themselves provide opportunities to connect socially and to switch from a negative mood to a positive one [21-22].

Mood management theory [23] asserts that people automatically pursue positive moods and avoid negative moods. This implies that when an event triggers a negative mood, such as stress, depression, or hostile feelings, people are willing to reverse that feeling. Moreover, uses and gratifications (U\&G) theory posits that individuals use certain media to satisfy specific needs [24]. In line with this notion, playing a favorite game as an instance of selective media use could be a useful tool to satisfy certain desires and needs of players [25]. Combining mood management and $U \& G$ theory suggests that some positive emotional experiences can be induced in the context of playing games.

Colwell [26] identified popular reasons for playing games among adolescents, which include companionship, fun, and stress relief. These results emphasized players' needs and desires to ameliorate negative moods as a reason for playing games. Russoniello and colleagues [21] found that playing games could enhance players' mood, boost relaxation, and alleviate anxiety. Therefore, gaming activities allow players to express their current feelings and leave behind a negative mental or psychological situation.

Nabi and colleagues [22] also reported that people with depressed mood seek out strategies that best allow them to ameliorate their feelings in a positive way. Thus, individuals may depend on playing favorite games to alleviate negative feelings or meet their needs for control that cannot be fulfilled in reality, as gaming allows them to satisfy certain desires. In other words, some individuals might use games as a means to cope with depression, loneliness, and stress. Additionally, some online games may be used to alleviate dysphoria and sadness associated with depression [27]. Further, research has shown benefits of using gaming as a mood repair tool [28].

For lonely individuals, the online environment may be an attractive way to enhance their social network and avoid social isolation [29, 30]. This environment provides access to countless others and an ideal social space in which one can satisfy his/her need to belong. Feelings of loneliness may result from unfulfilled desires and gaps between one's actual and desired social position. Thus, it is highly probable that individuals with such desires and gaps indulge in playing games to ameliorate their deficiencies in social ties. Specifically, playing online games may be the best way to socialize and avoid feelings of loneliness for such individuals [31]. Moreover, if aggression decreases, loneliness and depression would also decrease because of the ripple effect in mood contagion [32]. If this effect exists, it could also be affected by level of social intelligence among adolescent players.

\subsection{Parent- and peer-related factors}

With regard to relationships with parents, previous studies have reported that an undesirable parent-adolescent relationship might frustrate basic psychological needs [33], leading adolescents to pursue satisfaction of those needs via online gaming [34]. Therefore, parent relationships play an essential role in adolescent development.

Another critical factor for adolescent development is peer relationships. It is important for adolescents to make new friends or strengthen existing bonds. In this way, they can obtain reflections on their own thoughts and emotions [35], and peer relationships provide a means to integrate the process of self-definition [36]. Peer relationships have therefore emerged as a potentially important predictor of adolescents' psychosocial problems and of their well-being [37]. Emotional support from friends protects against negative social experiences, and can offer a counter to negative emotions [38]. Both parent and peer influence significantly affect adolescents' social functioning.

Playing games brings together players from 
around the world to interact with each other. These virtual interactions may satisfy game players' unfulfilled psychological needs, such as their internal desire for a sense of belonging and interpersonal connection [39, 40], leading to positive effects.

Some research has shown that playing games may increase negative emotions, but this applies only if the player is already psychologically vulnerable, and this may not be the case in the general population [41]. Furthermore, prior studies have reported that players can release their stress via certain games, even violent games [42, 43], and a game-based approach has emerged as an effective approach to stress management [44].

This implies that relief of negative emotions may vary according to players' internal states of social involvement, which may in turn be associated with social intelligence. Thus, we assumed that enjoying gameplay may elicit behavior conducive to the alleviation of negative emotions in highly socially intelligent players. Further, players who have close relationships with their parents and peers may experience positive outcomes. It is possible that social intelligence may be a confounding factor for outcomes of gameplay in the gaming population. Based on the above discussion, we will test the following hypotheses.

H1: The degree of players' a) aggression, b) depression, c) loneliness, and d) stress are negatively associated with the level of social intelligence.

H2: The degree of players' a) peer emotional support and $b)$ parent-child communication are positively associated with level of social intelligence.

RQ1: Is the level of social intelligence similar from time 1 to time 2 in terms of its relationship with aggression, depression, loneliness, stress, peeremotional support, and parent-child communication?

\section{Method}

\subsection{Sample}

We conducted a 2-wave longitudinal survey study among Korean adolescents. The age of respondents varied between 11 and 17 years $(\mathrm{M}=13.46, \mathrm{SD}=$ 2.48). In December 2015 (Time 1), a total of 2014 children and adolescents from primary and secondary schools participated by completing a survey. Parental consent was obtained by a professional research company, which carried out our survey processes. Six months later, in June 2016 (Time 2), we conducted the second wave (age: $\mathrm{M}=14.47, \mathrm{SD}=$
2.52). In the second wave, we were unable to reach 14 of our original respondents, mostly for personal reasons or unavailability. Of the remaining 2000 respondents, we were unable to match some questionnaires between waves because of discrepancies in respondents' names or student numbers. In total, 1639 respondents were matched between waves (i.e., by corresponding names or student numbers). Of these respondents, 1363 reported playing video games in both waves and had fully completed both questionnaires. Only these 1363 game-playing adolescents ( $51 \%$ boys and $49 \%$ girls) were included in our analyses.

\subsection{Measures}

Social intelligence was measured with the 21item Troms $\varnothing$ Social Intelligence Scale [45]. This scale includes 3 social intelligence subscales: social information processing, social skills, and social awareness. Responses are given on a 7-point scale (1 $=$ extremely poorly, $7=$ extremely well). T1: $\alpha=.901$, T2: $\alpha=.907$.

To measure aggression, the Short-Form BussPerry Aggression Questionnaire (BPAQ-SF) [46] was used. This 12-item scale is composed of 4 subscales: physical aggression, verbal aggression, anger, and hostility. Responses to the questionnaire are given on a 5-point Likert scale ( 1 = extremely uncharacteristic of me, $5=$ extremely characteristic of me). T1: $\alpha$ $=.895, \mathrm{~T} 2: \alpha=.902$.

Depression was measured with the Center for Epidemiologic Studies Depression Scale [47]. The scale items ask about the degree of sadness, gloominess, and so forth $(\alpha=.74)$ and are rated from 1 to 4 according to how often the symptoms are present $(1=$ never/rarely, $2=$ sometimes, $3=$ often, and $4=$ very often). T1: $\alpha=.886, \mathrm{~T} 2: \alpha=.884$.

Loneliness was measured with the UCLA Loneliness Scale [48]. This scale consists of 10 items designed to measure subjective feelings of loneliness as well as feelings of social isolation. The items are rated on a 4 -point scale $(1=$ strongly disagree, $4=$ strongly agree). T1: $\alpha=.770, \mathrm{~T} 2: \alpha=.799$.

In order to measure stress resulting from school performance and peer pressure, we used a short revised version of the Adolescent Stress Questionnaire (ASQ) with 2 sub-constructs [8]. This scale consists of 7 items rated on a 3 -point scale $(1=$ not at all, 3 = very often). Regarding stress from school performance, we asked participants about "Having to study things you do not understand," "Difficulty with some subjects," "Having to concentrate too long during school hours," and "Pressure to study." 


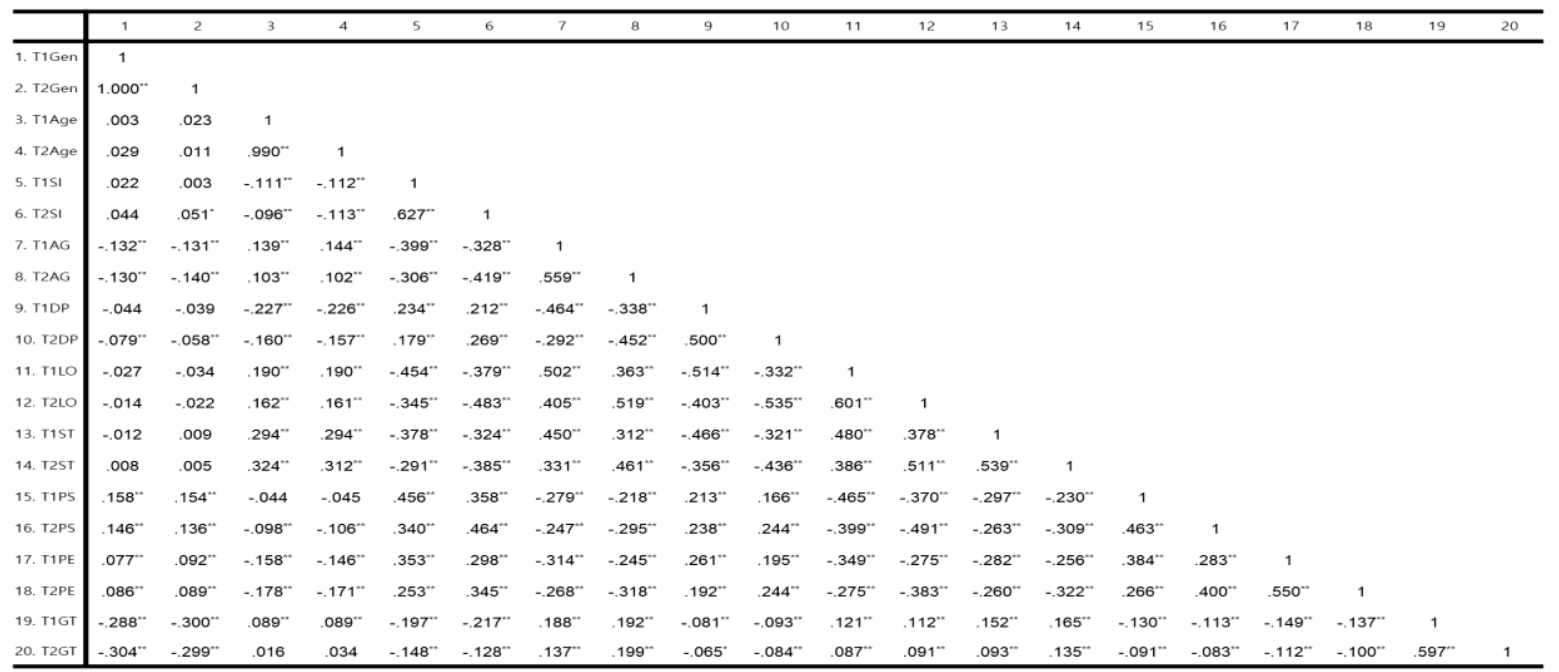

Figure 2. Correlations among the Variables.

$(\mathrm{SD}=88.34)$ at $\mathrm{T} 1$ and $113.20(\mathrm{SD}=92.39)$ minutes

Note. Gen=gender, $\mathrm{SI}=$ social intelligence, $\mathrm{AG}=$ aggression, $\mathrm{DP}=$ depression, $\mathrm{LO}=$ loneliness, $\mathrm{ST}=$ stress, $\mathrm{PS}=$ parent-child communication, $\mathrm{PE}=$ peer emotional support, $\mathrm{GT}=$ gaming time

For stress of peer pressure, we asked about "Pressure to fit in with peers," "Being judged by your friends," and "Disagreements between you and your peers." T1: $\alpha=.744, \mathrm{~T} 2: \alpha=.750$.

Parent-child communication was measured with the Parent-Child Communication Scale [49], which is used to assess communication between parents and children. This 3-item measure was adapted from the Revised Parent-Adolescent Communication short version developed by a Korean Game Panel Study.

We used the items "My parents and I talk to each other frequently," "My parents and I understand each other well," and "I can talk freely about anything with my parents." The items are rated on a 4-point scale $(1=$ strongly disagree, $4=$ strongly agree $)$. $\mathrm{T} 1$ : $\alpha=.832, \mathrm{~T} 2: \alpha=.870$.

We measured peer emotional support with 3 items involving perceptions that classmates liked the student as a person, e.g., "Students care about my feelings" [50]. This scale consists of 3 items rated on a 4-point scale $(1=$ strongly disagree, $4=$ strongly disagree). T1: $\alpha=.898, \mathrm{~T} 2: \alpha=.889$.

Daily online gaming time was measured by asking participants to report their average time spent playing games per day, from 1 (less than 30 minutes) to 8 (more than 6 hours).

\section{Results}

\subsection{Descriptive analysis}

The average amount of time adolescents spent playing games each day was about 108.54 minutes 


\begin{tabular}{|c|c|c|c|c|c|c|}
\hline Predictors & $\mathrm{B}$ & $\beta$ & $\mathrm{t}$ & Sig. & Tolerance & VIF \\
\hline T1 Aggression & -.197 & -.176 & -7.066 & .000 & .628 & 1.592 \\
\hline T1 Depression & -.199 & -.103 & -4.128 & .000 & .626 & 1.598 \\
\hline T1 Loneliness & -.255 & -.181 & -6.656 & .000 & .527 & 1.896 \\
\hline T1 Stress & -.233 & -.131 & -5.278 & .000 & .632 & 1.583 \\
\hline T1 Peer emotional support & .350 & .266 & 11.218 & .000 & .698 & 1.433 \\
\hline T1 Parent-child communication & .118 & .121 & 5.393 & .000 & .777 & 1.288 \\
\hline T1 Daily gaming time & -.052 & -.113 & -5.319 & .000 & .872 & 1.147 \\
\hline T1 Gender & -.150 & -.095 & -4.477 & .000 & .866 & 1.155 \\
\hline T1 Age & .003 & .010 & .475 & .635 & .889 & 1.125 \\
\hline & & & & & \multicolumn{2}{|c|}{$\begin{array}{r}\text { R-squared }=.363(\mathrm{p}<.001) \\
\text { Durbin-Watson }=1.965\end{array}$} \\
\hline Predictors & $\mathrm{B}$ & $\beta$ & $\mathrm{t}$ & Sig. & Tolerance & VIF \\
\hline T2 Aggression & -.154 & -.140 & -4.580 & .000 & .619 & 1.615 \\
\hline T2 Depression & -.130 & -.074 & -2.462 & .014 & .639 & 1.565 \\
\hline T2 Loneliness & -.187 & -.132 & -3.864 & .000 & .496 & 2.015 \\
\hline T2 Stress & -.132 & -.074 & -2.392 & .017 & .609 & 1.643 \\
\hline T2 Peer emotional support & .292 & .214 & 7.503 & .000 & .713 & 1.403 \\
\hline T2 Parent-child communication & .074 & .077 & 2.821 & .005 & .773 & 1.293 \\
\hline T2 Daily gaming time & -.060 & -.132 & -5.016 & .000 & .846 & 1.182 \\
\hline T2 Gender & -.166 & -.105 & -3.948 & .000 & .827 & 1.209 \\
\hline \multirow[t]{2}{*}{ T2 Age } & -.006 & -.017 & -.674 & .500 & .880 & 1.137 \\
\hline & & & & & \multicolumn{2}{|c|}{$\begin{array}{r}\text { R-squared }=.212(\mathrm{p}<.001) \\
\text { Durbin-Watson }=1.940\end{array}$} \\
\hline
\end{tabular}

Figure 3. Two Waves of Results

Note. Dependent Variable: Social intelligence at Time 1.

For psychosocial problem factors, social intelligence predicted variation in all four indicators. Specifically, social intelligence at Time 1 predicted lower levels of aggression, $\beta=-.176, p<.001$, depression, $\beta=-.103, p<.001$, loneliness, $\beta=-.181$, $\mathrm{p}<.001$, and stress regarding school performance and peer pressure, $\beta=-.131, \mathrm{p}<.001$. Regarding peer- and parent-related indicators, we found that social intelligence was related to higher scores in both peer emotional support, $\beta=.266, p<001$, and parent-child communication, $\beta=.121, \mathrm{p}<.001$. Interestingly, higher social intelligence at $\mathrm{T} 1$ predicted less daily gaming time, $\beta=-.113, \mathrm{p}<.001$.

The results at $\mathrm{T} 2$ were similar to those at $\mathrm{T} 1$. Social intelligence at $\mathrm{T} 1$ was associated with lower levels of aggression $(\beta=-.140, p<.001)$, depression $(\beta=-.074, p<.05)$, loneliness $(\beta=-.132, p<.001)$, and stress regarding school performance and peer pressure $(\beta=-.017, p<.001)$ at T2. Likewise, social intelligence at T1 was related to higher scores in both peer emotional support $(\beta=.214, \mathrm{p}<.001)$ and parent-child communication $(\beta=.077, \mathrm{p}<.01)$ at $\mathrm{T} 2$. Higher social intelligence at $\mathrm{T} 1$ also predicted less daily gaming time $(\beta=-.132, \mathrm{p}<.001)$ at $\mathrm{T} 2$.

\section{Discussion}

The overarching goal of this study was to illuminate how the enjoyment of games by players with high levels of social intelligence affects social outcomes (relationships with parents and peers) and psychosocial problem factors (aggression, depression, loneliness, and stress) in a 2-wave longitudinal survey of Korean adolescents.

As expected, players' level of social intelligence showed similar results on social and psychosocial problem factors 6 months later. The results suggest that social intelligence is negatively related to adverse emotions, and affected relationships with parents and peers in a positive way.

We analyzed the same person's survey data at a 6month interval and found that social intelligence in players predicted their negative feelings 6 months later. Specifically, more socially intelligent players reported reduced tendencies toward aggression, depression, stress, and loneliness over time.

Regarding relations with the alleviation of negative emotions, it is possible that socially intelligent adolescents use games as a coping tool. Because social intelligence includes the ability to regulate cognitive processes [20], highly socially intelligent players are more likely to be positively influenced by playing games. As a result, psychosocial problem factors were consistently lower 
for these players. It has already been documented that certain games can offer benefits to players, albeit with substantial risk [23, 42]. A diverse body of research has examined this perspective and shown that whether adolescents are dealing with physical or emotional pain, digital games can be a sufficient coping mechanism for them. This includes coping with chronic pediatric diseases [51], childhood cancer, post-traumatic stress disorder, and depression [52, 53].

Furthermore, many players use the attributes of the gaming arena as a means of seeking hedonic gratification $[25,26]$. In this context, media use is believed to be driven primarily by pleasure seeking and striving for the termination of unpleasant states $[42,43]$. Pleasant gaming experiences induce positive affective states in players. Accordingly, motivation for gaming has been found to involve the pursuit of social relationships, leisure time, entertainment, and relaxation [21, 34].

Regarding daily gaming time, socially intelligent players reported engaging in less time playing games 6 months later. These results imply that socially intelligent players might not use games excessively, instead playing them moderately. This is in line with previous findings that moderate gaming time can be beneficial for maintaining players' mental health, compared with non-players [54]. Thus, it is possible that socially intelligent players could derive more benefit from playing games, resulting in relatively less gaming time.

With respect to parental relationships, socially intelligent players reported more intimacy with their parents, showing positive effects over time. This is in line with previous studies and in support of attachment theory [55]. This theory posits that attachment behaviors can be strengthened via interaction with close caregivers like parents, who contribute most to the adolescent's formation of psychological structures that provide stability of the self, others, and the environment [56]. Although the majority of parents tend to see games as having a negative impact on their children [57], our results suggest that more socially intelligent players maintain more positive relationships with their parents, even while continuing to play games. Further research should investigate adding parents' perceptions of games and their relationship with their children's gaming activity to the analysis.

Regarding peer emotional support, socially intelligent players reported enhanced peer emotional support. Social support is associated with key health and well-being factors [58], such as decreased depression and reduced emotional problems [59]. Interpersonal relationships have been revealed to be an important factor during adolescence because they play a critical role in learning how to form and maintain satisfying long-term relationships [60], and may be important in preventing psychosocial problems [61]. In this study, players with a high level of social intelligence showed lasting positive relationships. Therefore, support from both parents and peers is vital among adolescent players with high social intelligence.

The social compensation hypothesis asserts that introverts and socially anxious adolescents who have difficulty maintaining and developing friendships are more likely to inhabit virtual worlds because they offer online contacts as an alternative to undesirable offline social relationships [61]. On the other hand, the social enhancement hypothesis posits that outgoing adolescents are motivated to add online contacts to their existing offline friends [62]. Therefore, it is likely that socially intelligent players have more outgoing personalities and thus enhanced social relationships. Further research should consider how a player's personality affects social intelligence according to introversion and extraversion.

Although there are mixed results in the literature on online game playing, variously demonstrating negative outcomes such as increased psychosocial problem factors (e.g., aggression or depression), null effects, or positive outcomes such as decreased psychosocial problem factors [63, 64, 65], this study found that those who had a high level of social intelligence reported lower levels of such negative emotions and enhanced relationships with both parents and peers 6 months later. Findings from this study will further help game-related researchers and practitioners to develop better strategies for addressing important internal factors that contribute to adolescents' social intelligence.

\section{References}

[1] H. Fuster, A. Chamarro, X. Carbonell, and R.J. Vallerand, "Relationship between Passion and Motivation for Gaming in Players of Massively Multiplayer Online Role-playing Games", Cyberpsychology, Behavior, and Social Networking 17 (5), 2014, pp. 292-297.

[2] A.V. Kokkinakis, J. Lin, D. Pavlas, and A.R. Wade, "What's in a Name? Ages and Names Predict the Valence of Social Interactions in a Massive Online Game", Computers in Human Behavior 55, 2016, pp. 605-613.

[3] A. Amialchuk and A. Kotalik, "Do Your School Mates Influence How Long You Game? Evidence from the U.S.”, PLoS One 11 (8), 2016, e0160664. 
[4] A.A. Raney, J.K. Smith, and K. Baker, Adolescents and the Appeal of Video Games, 2006.

[5] L.J. Crockett and A.C. Crouter, Pathways through Adolescence: Individual Development in Relation to Social Contexts, Psychology Press, New York, 2014.

[6] T.D. Cook and F.F. Furstenberg, Jr., "Explaining Aspects of the Transition to Adulthood in Italy, Sweden, Germany, and the United States: A Cross-disciplinary, Case Synthesis Approach", The Annals of the American Academy of Political and Social Science 580 (1), 2002, pp. 257-287.

[7] J.S. Eccles, A. Wigfield, and J. Byrnes, "Cognitive Development in Adolescence", Handbook of Psychology, 2003.

[8] D.G. Byrne, S. Davenport, and J. Mazanov, "Profiles of Adolescent Stress: The Development of the Adolescent Stress Questionnaire (ASQ)", Journal of Adolescence 30 (3), 2007, pp. 393-416.

[9] P. Qualter, S.L. Brown, P. Munn, and K.J. Rotenberg, "Childhood Loneliness as a Predictor of Adolescent Depressive Symptoms: An 8-year Longitudinal Study", European Child \& Adolescent Psychiatry 19 (6), 2010, pp. 493-501.

[10] B.J. Leadbeater, S.J. Blatt, and D.M. Quinlan, "Gender-linked Vulnerabilities to Depressive Symptoms, Stress, and Problem Behaviors in Adolescents", Journal of Research on Adolescence 5 (1), 1995, pp. 1-29.

[11] J. Panicker and R. Sachdev, "Relations among Loneliness, Depression, Anxiety, Stress and Problematic Internet Use", International Journal of Research in Applied, Natural and Social Sciences 2 (9), 2014, pp. 1-10.

[12] A. Kaukiainen, K. Björkqvist, K. Lagerspetz, K. Österman, C. Salmivalli, S. Rothberg, and A. Ahlbom, "The Relationships between Social Intelligence, Empathy, and Three Types of Aggression", Aggressive Behavior 25 (2), 1999, pp. 81-89.

[13] N. Cantor and J.F. Kihlstrom, Personality and Social Intelligence, Pearson College Division, 1987.

[14] J.F. Kihlstrom and N. Cantor, "Social Intelligence", Handbook of Intelligence, 2000, pp. 359-379.

[15] S.J. Zaccaro, J.A. Gilbert, K.K. Thor, and M.D. Mumford, "Leadership and Social Intelligence: Linking Social Perspectiveness and Behavioral Flexibility to Leader Effectiveness", The Leadership Quarterly 2 (4), 1991, pp. 317-342.

[16] D. Tang and B.J. Schmeichel, "Stopping Anger and Anxiety: Evidence that Inhibitory Ability Predicts Negative Emotional Responding", Cognition \& Emotion 28 (1), 2014, pp. 132-142.
[17] B.M. Wilkowski, M.D. Robinson, and W. TroopGordon, "How Does Cognitive Control Reduce Anger and Aggression? The Role of Conflict Monitoring and Forgiveness Processes", Journal of Personality and Social Psychology 98 (5), 2010, p. 830.

[18] C.H. Shen, P. Monge, and D. Williams, "The Evolution of Social Ties Online: A Longitudinal Study in a Massively Multiplayer Online Game", Journal of the Association for Information Science and Technology 65 (10), 2014, pp. 2127-2137.

[19] M. Wallenius, R.-L. Punamäki, and A. Rimpelä, "Digital Game Playing and Direct and Indirect Aggression in Early Adolescence: The Roles of Age, Social Intelligence, and Parent-Child Communication", Journal of Youth and Adolescence 36 (3), 2007, pp. 325-336.

[20] J.P. Guilford and R. Hoepfner, The Analysis of Intelligence, McGraw-Hill Companies, 1971.

[21] C.V. Russoniello, K. O'Brien, and J.M. Parks, “The Effectiveness of Casual Video Games in Improving Mood and Decreasing Stress", Journal of Cyber Therapy and Rehabilitation 2 (1), 2009, pp. 53-66.

[22] R.L. Nabi and M.B. Oliver, The SAGE Handbook of Media Processes and Effects, Sage, 2009.

[23] L. Reinecke, R. Tamborini, M. Grizzard, R. Lewis, A. Eden, and N.D. Bowman, "Characterizing Mood Management as Need Satisfaction: The Effects of Intrinsic Needs on Selective Exposure and Mood Repair", Journal of Communication 62 (3), 2012, pp. 437-453.

[24] D.K. Davis and S. Baran, Mass Communication Theory: Foundations, Ferment, and Future, Thomson Wadsworth, Belmont, CA, 2006.

[25] J. McGonigal, Reality Is Broken: Why Games Make Us Better and How They Can Change the World, Penguin, 2011.

[26] J. Colwell, "Needs Met through Computer Game Play Among Adolescents", Personality and Individual Differences 43 (8), 2007, pp. 2072-2082.

[27] J. Morahan-Martin and P. Schumacher, "Incidence and Correlates of Pathological Internet Use among College Students", Computers in Human Behavior 16 (1), 2000, pp. 13-29.

[28] J.B. Weaver, D. Mays, S.S. Weaver, W. Kannenberg, G.L. Hopkins, D. Eroĝlu, and J.M. Bernhardt, "Health-Risk Correlates of Video-game Playing among Adults", American Journal of Preventive Medicine 37 (4), 2009, pp. 299-305.

[29] L.H. Shaw and L.M. Gant, "In Defense of the Internet: The Relationship between Internet Communication and 
Depression, Loneliness, Self-Esteem, and Perceived Social Support”, Cyberpsychology \& Behavior 5 (2), 2002, pp. 157-171.

[30] M. Konnikova, The Confidence Game: Why We Fall for It ... Every Time, Penguin, USA, 2016.

[31] M.D. Griffiths and A. Meredith, "Videogame Addiction and Its Treatment", Journal of Contemporary Psychotherapy 39 (4), 2009, pp. 247-253.

[32] S.G. Barsade, "The Ripple Effect: Emotional Contagion and Its Influence on Group Behavior", Administrative Science Quarterly 47 (4), 2002, pp. 644675.

[33] M. Joussemet, R. Landry, and R. Koestner, "A Selfdetermination Theory Perspective on Parenting", Canadian Psychology/Psychologie Canadienne 49 (3), 2008, p. 194.

[34] R.M. Ryan, C.S. Rigby, and A. Przybylski, "The Motivational Pull of Video Games: A Self-determination Theory Approach", Motivation and Emotion 30 (4), 2006, pp. 344-360.

[35] A. Fitzgerald, N. Fitzgerald, and C. Aherne, "Do Peers Matter? A Review of Peer and/or Friends' Influence on Physical Activity among American Adolescents", Journal of Adolescence 35 (4), 2012, pp. 941-958.

[36] W.M. Bukowski, C. Motzoi, and F. Meyer, "Friendship as Process, Function, and Outcome", Handbook of Peer Interactions, Relationships, and Groups, 2009, pp. 217-231.

[37] I.M. Shochet and C.L. Smith, "A Prospective Study Investigating the Links among Classroom Environment, School Connectedness, and Depressive Symptoms in Adolescents", Psychology in the Schools 51 (5), 2014, pp. 480-492.

[38] L. Bond, J.B. Carlin, L. Thomas, K. Rubin, and G. Patton, "Does Bullying Cause Emotional Problems? A Prospective Study of Young Teenagers", British Medical Journal 323 (7311), 2001, pp. 480-484.

[39] E.L. O'Connor, H. Longman, K.M. White, and P.L. Obst, "Sense of Community, Social Identity and Social Support Among Players of Massively Multiplayer Online Games (MMOGs): A Qualitative Analysis", Journal of Community and Applied Sociology 25 (6), 2015, pp. 459473.

[40] J. Billieux, M. Van der Linden, S. Achab, Y. Khazaal, L. Paraskevopoulos, D. Zullino, and G. Thorens, "Why Do You Play World of Warcraft? An In-depth Exploration of Self-Reported Motivations to Play Online and In-game Behaviours in the Virtual World of Azeroth", Computers in Human Behavior 29 (1), 2013, pp. 103-109.
[41] C.J. Ferguson, "Does Movie or Video Game Violence Predict Societal Violence? It Depends on What You Look at and When", Journal of Communication 65 (1), 2015, pp. 193-212.

[42] L. Reinecke, "Games and Recovery: The Use of Video and Computer Games to Recuperate from Stress and Strain", Journal of Media Psychology 21 (3), 2009, 126142.

[43] D.M. Shafer, "Causes of State Hostility and Enjoyment in Player versus Player and Player versus Environment Video Games", Journal of Communication 62 (4), 2012, pp. 719-737.

[44]. L. Chittaro and R. Sioni, "Affective Computing vs. Affective Placebo: Study of a Biofeedback-controlled Game for Relaxation Training", International Journal of Human-Computer Studies 72 (8), 2014, p. 663-673.

[45] D. Silvera, M. Martinussen, and T.I. Dahl, "The Troms $\varnothing$ Social Intelligence Scale, a Self-report Measure of Social Intelligence", Scandinavian Journal of Psychology 42 (4), 2001, pp. 313-319.

[46] P.M. Diamond, E.W. Wang, and J. Buffington-Vollum, "Factor Structure of the Buss-Perry Aggression Questionnaire (BPAQ) with Mentally Ill Male Prisoners", Criminal Justice and Behavior 32 (5), 2005, pp. 546-564.

[47] P.M. Lewinsohn, J.R. Seeley, R.E. Roberts, and N.B. Allen, "Center for Epidemiologic Studies Depression Scale (CES-D) as a Screening Instrument for Depression among Community-residing Older Adults", Psychology and Aging 12 (2), 1997, p. 277.

[48] D.W. Russell, "UCLA Loneliness Scale (Version 3): Reliability, Validity, and Factor Structure", Journal of Personality Assessment 66 (1), 1996, p. 20-40.

[49] M.D. Krohn, S.B. Stern, T.P. Thornberry, and S.J. Jang, "The Measurement of Family Process Variables: The Effect of Adolescent and Parent Perceptions of Family Life on Delinquent Behavior", Journal of Quantitative Criminology 8 (3), 1992, pp. 287-315.

[50] D.W. Johnson and R. Johnson, "Social Interdependence and Perceived Academic and Personal Support in the Classroom", Journal of Social Psychology 120 (1), 1983, pp. 77-82.

[51] D.A. Lieberman, "Designing Serious Games for Learning and Health in Informal and Formal Settings", Serious Games: Mechanisms and Effects, 2009, pp. 117130.

[52] A.S. Rizzo, B. Lange, E.A. Suma, and M. Bolas, "Virtual Reality and Interactive Digital Game Technology: New Tools to Address Obesity and Diabetes", Journal of Diabetes Science and Technology 5 (2), 2011, pp. 256-264. 
[53] E. Rahmani, S.A. Boren, "Videogames and Health Improvement: A Literature Review of Randomized Controlled Trials", Games for Health: Research, Development, and Clinical Applications 1 (5), 2012, pp. 331-341.

[54] H. Allahverdipour, M. Bazargan, A. Farhadinasab, and B. Moeini, "Correlates of Video Games Playing among Adolescents in an Islamic Country", BMC Public Health 10 (1), 2010, p. 286.

[55] J. Cassidy, Handbook of Attachment: Theory, Research, and Clinical Applications, Rough Guides, 1999.

[56] I.M. Shochet, R. Homel, W. Cockshaw, D.T. Montgomery, "How Do School Connectedness and Attachment to Parents Interrelate in Predicting Adolescent Depressive Symptoms?", Journal of Clinical Child \& Adolescent Psychology 37 (3), 2008, pp. 676-681.

[57] V. Rideout, "Parents, Children \& Media: A Kaiser Family Foundation Survey", Henry J. Kaiser Family Foundation, 2007.

[58] B.N. Uchino, J.T. Cacioppo, and J.K. Kiecolt-Glaser, "The Relationship between Social Support and Physiological Processes: A Review with Emphasis on Underlying Mechanisms and Implications for Health", Psychological Bulletin 119 (3), 1996, p. 488.

[59] M. Helsen, W. Vollebergh, and W. Meeus, "Social Support from Parents and Friends and Emotional Problems in Adolescence", Journal of Youth and Adolescence 29 (3), 2000, pp. 319-335.

[60] J. Connolly, W. Furman, and R. Konarski, "The Role of Peers in the Emergence of Heterosexual Romantic Relationships in Adolescence", Child Development 71 (5), 2000, pp. 1395-1408.

[61] P.M. Valkenburg, A.P. Schouten, and J. Peter, "Adolescents' Identity Experiments on the Internet", New Media \& Society 7 (3), 2005, pp. 383-402.

[62] R. Kraut, S. Kiesler, B. Boneva, J. Cummings, V. Helgeson, and A. Crawford, "Internet Paradox Revisited", Journal of Social Issues 58 (1), 2002, pp. 49-74.

[63] B.J. Bushman and L.R. Huesmann, "Twenty-Five Years of Research on Violence in Digital Games and Aggression Revisited", European Psychologist 19 (1), 2014, pp. 47-55.

[64] M. Elson and C.J. Ferguson, "Twenty-Five Years of Research on Violence in Digital Games and Aggression", European Psychologist 19 (1), 2014, pp. 33-46.

[65] C.J. Ferguson, C. San Miguel, A. Garza, and J.M. Jerabeck, "A Longitudinal Test of Video Game Violence Influences on Dating and Aggression: A 3-Year
Longitudinal Study of Adolescents", Journal of Psychiatric Research 46 (2), 2012, pp. 141-146. 